\title{
Operations Management in Ambulatory Care in Switzerland
}

\author{
Vinzenz UHR ${ }^{1}$, Marc T. GAUCH ${ }^{1}$, and Kerstin DENECKE ${ }^{2}$ \\ Bern University of Applied Sciences, Bern, Switzerland
}

\begin{abstract}
Practice efficiency is influenced by its operations management. We aim at studying implementation of operations management in Swiss medical practices and we develop a dashboard that allows controlling and managing resources. To study operations management and relevant indicators in ambulant care, we distributed questionnaires by e-mail and conducted 6 interviews. In collaboration with a group practice, we collected requirements regarding a dashboard for operations management, developed a mockup and finally a prototype. This prototype was deployed and implemented in daily routine. From the assessments we learned that practice information systems (PIS) are not sufficiently supporting production planning and control. Relevant indicators include processing time per patient or waiting time for quantifying efficiency and identify potential improvements in production. Within 5 weeks of implementation of our dashboard in a group practice, we learned that calculating indicators and support of operations management by means of a dashboard is well appreciated by practice employees. Indicators are considered extremely useful for operations management.
\end{abstract}

Keywords. Efficiency, general practice, organization and administration, outpatients

\section{Introduction}

Since 2000, health care costs in Switzerland are rising continuously in average by $3.5 \%$ per year. Their share of the gross domestic product (GDP) also increased by $2 \%$. In 2018 , a new peak was reached with CHF 80 '2 242 million health care costs per year $(11.2 \%$ of the GDP) [1]. Furthermore in ambulant care, inefficiency is prevalent in nonclinical processes involved in patient care, from scheduling to test result reporting to prescription refills. In this context, inefficiency can be defined as using more inputs (or resources) than is necessary to deliver patient care or a health care service [2] and it is connected to unnecessary variation in operational and clinical processes [3].

Registered doctors in ambulant care have a dual role: as physicians they are concerned about the health of their patients. As entrepreneurs, the economic health of their practice in terms of revenue growth is essential. Improving the efficiency of a medical practice not only has economic advantages. For example, optimising processes leads to more satisfied employees, reduction of stress and burnout [4]. Satisfied employees are friendlier, more pro-active and make less mistakes. This in turn has an impact on patients, who in turn are more satisfied with the medical attendance [5].

\footnotetext{
${ }^{1}$ Contributed equally

${ }^{2}$ Corresponding author: Kerstin Denecke, Bern University of Applied Sciences, Biel / Bienne, Switzerland; E-mail: kerstin.denecke@bfh.ch
} 
In principal, practice efficiency is influenced by operations management. Operations management is an area of management concerned with designing and controlling the process of production. Production as an operational function has the task of planning and controlling the healthcare service provision process [6]. In a medical practice, production consists of the provision of healthcare services. While production planning is responsible for scheduling patient appointments and the associated planning of resources (staff, equipment, rooms and materials), production control focuses on the smooth execution of processes. This includes room allocation, equipment use and the allocation of orders to an medical practice assistant (MPA). Production management is carried out dynamically by the MPA. In principal, medical practices are supported in operations management by their practice software, the practice information system (PIS). Such systems for storing and managing patient data are in use in $77 \%$ of Swiss medical practices [7].

Process improvements related to inefficiency for reducing health care costs have been considered mainly for inpatient processes [8,9]. Limited work considered operations management and the resources dedicated to primary care [4]. James et al. identified several sources for inefficiencies in medical practices [4]. They include activities related to making appointments and scheduling during pre-visit of a patient, practice layout, communication staffing during the visit and medication refills, managing examination results during post-visit.

In this work, the operations management in Swiss medical practices is investigated, specifically focussing on the activities and processes during the visit of patients. We want to find out to what extent the operations management is supported by available PIS. To assist operations management, a dashboard is developed, deployed and implemented in a medical practice. A quantitative study is conducted to determine whether an increase in efficiency can be achieved using the application.

\section{Methods}

\subsection{Analysis of current situation of operations management in Swiss medical practices}

To collect information on processes and problems in operations management in Swiss medical practices, we sent e-mails to chains of medical practices and ambulatory clinics. In these e-mails, we asked for problems in operations management that occur in daily routine. Further, we asked for a telephone interview. The interviews were based on a questionnaire that was extended when new questions popped up in an interview. Questions concerned problems in the internal coordination of personnel and structural resources, problems in the process control and important indicators for process control. To identify relevant medical practices, we searched for chains of clinical practices in Switzerland using Google (search terms: "Gruppenpraxis Schweiz", "Gruppenpraxen Ketten schweiz", "Grösste Arztpraxisketten Schweiz"). A list with the largest chains could be identified [10]. From this list, we contacted 12 practices located in Switzerland. Besides these chains, we contacted 9 ambulatory care clinics and polyclinics. In total, 21 practices were contacted; $13(62 \%)$ did not replied. Three practices described their processes by e-mail and with six practices, we conducted interviews with either MPA, director or physicians. Additionally, 20 German-speaking provider of PIS were contacted by e-mail and were asked how their PIS supports the process control. The provider were identified using the FMH Swiss Medical Association Softwarekatalog [11]. 8 of 20 provider replied by e-mail. 


\subsection{Development and implementation of a dashboard for process control and planning}

The development of the dashboard for process control and management was realized in an iterative process following principles of human-centred design (DIN EN ISO 9241210). This means future users were involved in the whole process and contributed actively with information and feedback. In a first phase, requirements were collected in interviews with employees of a concrete group practice; existing process management and control procedures and their limitations were analyzed. Mockups were created and a scenario-based usability test was conducted with the mockup and MPAs from the group practice. We adapted the design and functionalities of the dashboard according to the feedback and implemented a prototype.

We conducted a deployment phase of 2 weeks followed by an implementation phase of 5 weeks. The dashboard was deployed in a group practice ( 8 physicians and 10 other healthcare staff) between 02.11.2020 and 15.11.2020. One MPA in this practice is responsible for production control. She allocates patients to rooms in time and ensures that relevant documents for the patient-doctor encounter are available. She ensures a smooth routine of processes which requires concentration. If successful, at the end of the day all patients have been treated within the consultation hours. If not successful, the leading MPA has to support the team in treating patients. During that time, she cannot complete her actual tasks which leads to overtime hours. In the deployment phase, staff was trained using a user manual. All MPA were able to use the tool after these two weeks. During five following weeks (implementation phase), the application was used in routine and we collected data on the efficiency of processes. As indicator to assess efficiency, we compared the number of overtime hours of the leading MPA before and after implementation of the tool. For this purpose, we accessed the overtime hours during the period 01.01.2020 and 18.12.2020. We removed days, where the MPA worked less than 7 hours or took time off in lieu.

\section{Results}

\subsection{Production control and management in Swiss medical practices}

As means to support operations management, we identified: agenda, careful scheduling, and consultation templates. In the following, more details on these means are provided together with challenges.

Four $(\mathrm{n}=8)$ medical practices consider careful scheduling and an agenda as the most important factor for successful operations management. The agenda should contain the patient appointments with doctors and the reservation of required resources. Making appointments with patients is carried out by telephone. In case the scheduling for a specific appointment is inappropriate, time for consultations might be too short or too long. Thus, the required resources might be unavailable when needed resulting in waiting times for patients or additional appointments. In five group practices, the telephone service is realized by the MPA and supported with templates of appointments. These templates are derived from process control data: For the most frequent appointments, past consultations are used to record the appointment duration, required resources, or material (e.g. duration for a normal examination 15'). All interview partners confirmed that preparing consultation templates is more trivial for a practice with specialists than a practice in family medicine. Specialists mainly treat patients with a concrete admission diagnosis 
which allows for more precise planning of equipment and staff. A family doctor is confronted with more heterogeneous and diffuse complaints and the list of diagnoses can often only be narrowed down during the consultation. For more precise scheduling, one of the outpatient clinics employs nursing staff on the telephone service. The nursing staff, who have more advanced training than the MPA, can perform already some kind of triage and can allocate resources to the consultations more precisely.

Production control is responsible for carrying out the planning. In six practices, this task is distributed among all MPA, and in one group practice it is taken over by a single MPA. One problem with a group practice is the overcrowded waiting room. In stressful situations, the overview is lost, patients are forgotten and the routine is disrupted. Five medical practices consider standardisation of processes as the best means to increase efficiency. According to them, defined roles, task and priority lists for the MPAs would enable a smooth process.

Table 1. Indicators on operations management and use for process control and management.

\begin{tabular}{|c|c|}
\hline Indicator & Description \\
\hline $\begin{array}{l}\text { Average processing time per } \\
\text { patient }\end{array}$ & $\begin{array}{l}\text { Average duration of a stay of a patient in the practice from entering } \\
\text { the practice until leaving the practice }\end{array}$ \\
\hline $\begin{array}{l}\text { Average processing time of a } \\
\text { patient per reason of visit }\end{array}$ & $\begin{array}{l}\text { Average processing time per reason of visit (enables more precise } \\
\text { process planning and scheduling) }\end{array}$ \\
\hline $\begin{array}{l}\text { Average processing time of a } \\
\text { specific patient }\end{array}$ & $\begin{array}{l}\text { Average processing time of a specific patient independent of reason } \\
\text { per visit. }\end{array}$ \\
\hline $\begin{array}{l}\text { Processing time of a patient } \\
\text { per specific employee }\end{array}$ & $\begin{array}{l}\text { Average processing time per employee aims to identify bottlenecks } \\
\text { and processing delays }\end{array}$ \\
\hline Waiting time & $\begin{array}{l}\text { Average time spent in the practice starting with the scheduled ap- } \\
\text { pointment time in the waiting room. Aims at identifying potentials } \\
\text { for optimiziation. }\end{array}$ \\
\hline Delay of patient & Average delay of a patient shows potentials for optimization. \\
\hline $\begin{array}{l}\text { No show without giving no- } \\
\text { tice }\end{array}$ & Number and reasons for no shows to identify cluster \\
\hline $\begin{array}{l}\text { Percentage of time used for } \\
\text { administrative tasks per pa- } \\
\text { tient }\end{array}$ & $\begin{array}{l}\text { Identify optimization potentials (e.g. by hiring an employee that can } \\
\text { help with administrative tasks to relieve the healthcare staff) }\end{array}$ \\
\hline $\begin{array}{l}\text { Accounted time versus actual } \\
\text { time used by physician for } \\
\text { one patient }\end{array}$ & $\begin{array}{l}\text { Used to identify wrong or not accounted consultations and to adapt } \\
\text { documentation of services in time }\end{array}$ \\
\hline
\end{tabular}

One outpatient clinic distributes patients to decentralised waiting areas, as opposed to the classic waiting room. Depending on the required action, a patient takes a seat in a different area. There are different waiting areas, e.g. a waiting area for consultations with the doctors, one for consultations with the nursing staff and in front of each consulting room there is space for one person to wait for access to the corresponding consulting room.

Empty times (unproductive time of the doctors) occur when patients are late or in case of unannounced absences (no show). For two practices, this has become the biggest problem in the area of operations management. Sending reminders in the form of e-mails and text messages reduces but does not completely prevent of no shows.

One group practice is planning to implement an alternative approach to operations management from January 2021 based on lean principles [12]: the patient no longer moves through the different rooms within a practice, but is placed in an empty room and the healthcare professionals and required resources comes to him. 
A practice's processes depend on the functionalities of its practice software. All PIS surveyed offer an agenda module for production planning. The appointments can be stored with a status (e.g. 'in the waiting room' or 'cancelled'), which can be freely configured in some cases depending on the software. This allows to allocate rooms and locate the patient. Five PIS additionally support the process control with an open issue tracker system. This system can be used to digitally transmit orders from the doctor to the MPA. In one of the PIS, priorities can be assigned to the orders by the physician. This replaces manual prioritisation by an MPA.

The interviews with the medical practices revealed that they would be interested in the indicators listed in table 1. However, none of the PIS calculates indicators useful for operations management from production data.

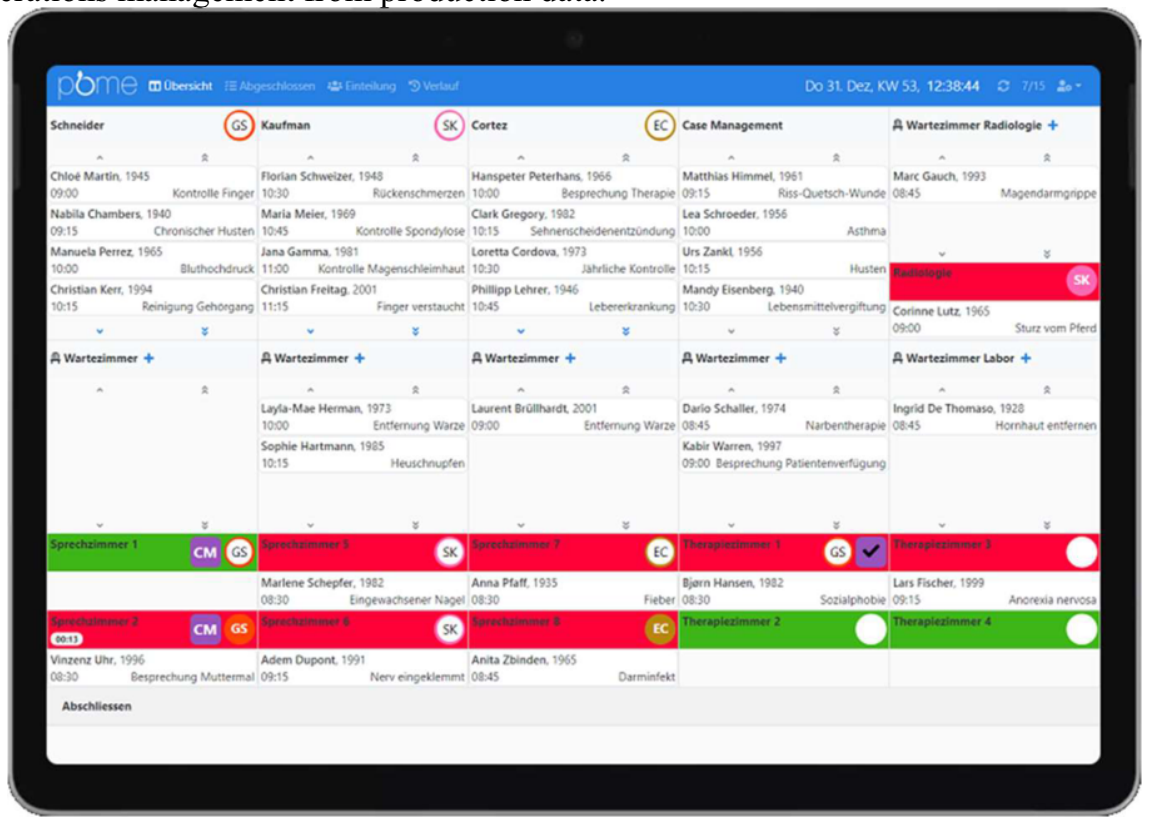

Figure 1. Dashboard for process control and management. For each physician, one column is assigned. Each column comprises three sections: agenda, waiting room, consulting room. Green colour indicates an empty consulting room; red colour an occupied consulting room.

\subsection{Dashboard for process control and management}

Our application is web-based and supports production control in a group practice. In particular, the functionalities are as follows (Fig. 1): The dashboard provides an overview on the production status of resources (availability of rooms, medical devices), patients (scheduled, awaiting treatment, under treatment), physicians and MPA. Patient names show up as scheduled and are assigned to the physician as scheduled. Location of the patient can be changed by drag and drop, i.e. the patient name can be moved to a waiting room once the patient shows up in the practice, moved forward to the consulting room or can even be checked out when the patient leaves the practice. Beyond, the location of physicians can be changed. The process control, i.e. changing the location of patient or physician names has to be realized by an MPA. A user can trigger manually a synchronisation. Production and process data can be extracted to calculate indicators. 
Vue.js was used to create the Javascript single-page application. The library VueDraggable was exploited to realize user control by touch and mouse controller. The system is running under Windows. It is supposed to be used on a tablet. An ICS interface has been implemented to connect the dashboard to the PIS. An ICS interface allows to import calendar data into corresponding programs such as Microsoft Outlook. The concrete interface has been implemented for the PIS provided by the software company Vitodata. Appointment data is send from the PIS to the ICS-Server of Vitodata. Data from this server can be accessed via Internet. Appointment data can be downloaded from the server as text file. The dashboard can be adapted easily to the infrastructure (rooms, medical devices, personnel) of a practice. When the dashboard application is started, the ICS data is collected from the server and shown in the dashboard. After that initialization, updates of appointments are made every 15 minutes.

\subsection{Evaluation of Efficiency}

Overtime hours of leading MPA are shown in Figure 2. 145 data points before deployment of the tool and 18 data points in the deployment phase have been considered. In an implementation phase of five weeks, we could not yet proof that efficiency can be significantly increased by using the dashboard. Reasons for this might be due to the chosen indicator (overtime hours of the leading MPA). This indicator can be impacted also by other factors such as unusual increase of patients due to the current pandemic situation. Another indicator to be considered would be processing time per patient. We did not used this indicator in our study since we were missing the baseline data which would have been too complicated to collect in a reasonable amount of time and during the current COVID-19 pandemic situation might lead to non-representative data. Other research demonstrated that patient flow analysis is well suited for assessing efficiency of patient visits in primary care [13]. We can recognize some peaks in the overtime hours; unfortunately, no information on reasons of overtime hours are recorded in the time recording system.

\section{Discussion}

In this paper, we introduced a dashboard that supports production control in a medical practice. The application offers several benefits: at any time information on the production status of patients, physicians, MPA and resources is accessible and they can be easily localised. Indicators for operations management and control such as processing time per patient, time spent in the waiting room, or average delay of a patient can be calculated based on the production data that are stored by the application.

The dashboard can be easily adapted to other configurations of medical practices. Names of physicians or MPA and their working days can be added as well as additional waiting rooms and consulting rooms. In its current implementation, a user has to actively change the status of physicians and patients. The workflow could be facilitated when for example the localisation of the physician (in which consulting room he/she is at the moment) changes automatically. This would require some passive tracking sensors in the various locations. 


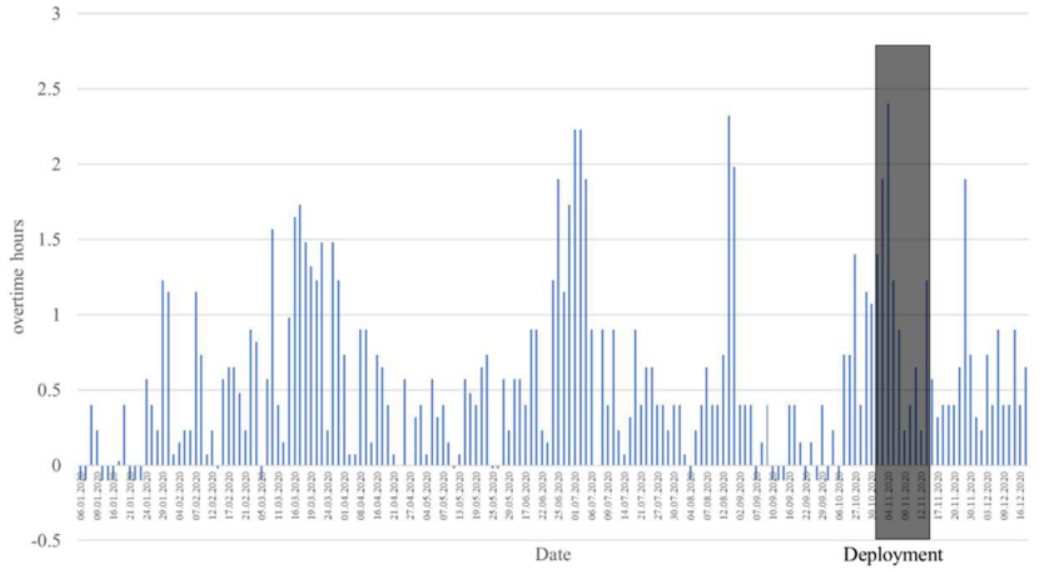

Figure 2. Overtime hours of leading MPA

Our application was developed as locally running tablet application. A server-based application might have been another, if not even better option since this would allow several users to interact with the dashboard. Our decision regarding system architecture has been made based on the interviews in the group practice where we found out that the application will only be used by one MPA. Throughout the implementation phase, it turned out that more users need access to the tool.

Our approach directly transfers knowledge from other assessments of factors that impact physicians' well-being and for increasing practice efficiency. These studies found out that interventions such as pre-visit planning, or optimization of patient flow through clinics, may reduce burnout and improve engagement [14]. Our work focused on improving patient flow during a visit in a medical practice by means of a dashboard. Use of dashboards in medical settings has already been suggested for displaying information for emergency medical services [15] or for supporting decision making. Pestana et al. [16] developed dashboards to improve health care management in hospitals. To the best of our knowledge, no approach similar to our dashboard has been reported so far for ambulatory care.

\section{Conclusion}

In this work, we assessed the current state and needs of operations management in Swiss medical practices. We recognized that there is a need for support in operations management that existing PIS do not sufficiently provide, mainly provision of indicators for process control. Extensions of PIS by a dashboard as we suggested in this work would be desirable. At least calculating and controlling indicators such as waiting time, processing time of patients etc. should be enabled for improving operations management. These indicators are essential for operations management.

\section{Conflict of interest}

VU is working as ICT Business Analyst at Swisscom Health AG in the context of the practice information system curaMED. 


\section{References}

[1] Bundesamt für Statistik, Kosten und Finanzierung des Gesundheitswesens seit 1960, https://www.bfs.ad$\mathrm{min} . \mathrm{ch} / \mathrm{bfs} / \mathrm{de} / \mathrm{home} / \mathrm{aktuell} /$ neue-veroeffentlichungen.assetdetail.14840802.html, last access: 15.01.2021

[2] James B, Bayley KB Cost of poor quality or waste in integrated delivery system settings. AHRQ Publication No. 290-00-0018. Rockville, Md.: Agency for Healthcare Research and Quality; 2006

[3] Litvak E, Buerhaus PI, Davidoff F, Long MC, McManus ML, Berwick DM. Managing unnecessary variability in patient demand to reduce nursing stress and improve patient safety. The Joint Commission Journal on Quality and Patient Safety. 2005 Jun 1;31(6):330-8.

[4] James KA, Ross SE, Vance B, Radcliffe T, Harrison MI, West D. Inefficiency in primary care: common causes and potential solutions. Family Practice Management. 2015 Apr;22(2):18-22.

[5] Nowak T. Optimierungsmöglichkeiten einer Arztpraxis: Organisation, Mitarbeiterführung und Marketing, http://www.wiso-net.de/document/DIPL,ADIP\%5F 9783836615242197, last access: 15.01.2021

[6] Thommen J-P. Managementorientierte Betriebswirtschaftslehre. 8. edition, Versus Verl, Zürich, 2008. pp. 275

[7] Golder L, Jans C, Melanie I, Kress J. Swiss eHealth Barometer 2020, gfs.bern, Bern, 2020

[8] McCulloch P, Kreckler S, New S, Sheena Y, Handa A, Catchpole K. Effect of a "Lean" intervention to improve safety processes and outcomes on a surgical emergency unit. Bmj. 2010 Nov 2;341.

[9] Spagnol GS, Min LL, Newbold D. Lean principles in Healthcare: an overview of challenges and improvements. IFAC Proceedings Volumes. 2013 Sep 1;46(24):229-34.

[10] Seiler R. Das rentable Geschäft mit Schweizer Arztpraxen, https://www.handelszeitung.ch/panorama/long-read/das-rentable-geschaft-mit-schweizer-arztpraxen?page=2\#page, last access: 15.01.2021

[11] FMH Services, Software 2020 für die Praxisadministration, https://www.fmhservices.ch/softwarekatalog, last access: 15.01.2021

[12] Endsley S, Magill MK, Godfrey MM., Creating a lean practice, Fam Pract Manag. 2006:13(4), 34-8.

[13] Potisek NM, Malone RM, Shilliday BB et al. Use of patient flow analysis to improve patient visit efficiency by decreasing wait time in a primary care-based disease management programs for anticoagulation and chronic pain: a quality improvement study. BMC Health Serv Res 7, 8 (2007).

[14] Tawfik DS, Profit J, Webber S, Shanafelt TD. Organizational factors affecting physician well-being. Current treatment options in pediatrics. 2019 Mar 15;5(1):11-25.

[15] Christen O, Mösching Y, Müller P, Denecke K, Nüssli S. Dashboard Visualization of Information for Emergency Medical Services, Stud Health Technol Inform. 2020 Nov 23;275:27-31.

[16] Pestana M, Pereira R, Moro S. Improving Health Care Management in Hospitals Through a Productivity Dashboard. Journal of Medical Systems. 2020 Apr;44(4):1-9. 